\title{
HIPST—History and Philosophy in Science Teaching: A European Project
}

\author{
Dietmar Höttecke
}

Published online: 11 January 2012

(C) Springer Science+Business Media B.V. 2012

Readers of this journal usually do not have to be convinced any more that teaching and learning science with history and philosophy of science (HPS) might be beneficial on several levels. Plenty of articles have commenced with arguing for an extended implementation of HPS on different fields of science teaching like school science education, teacher training, vocational training and science museums. Nevertheless, advocates of HPS very often belong to the group of academic staff (like I do). Even though many authors have a background as science teachers, there are just a few who managed to stay close to the practices and realities of school science education after having adopted a position as a researcher. No wonder that bridges have to be built between the academic cultures of the advocates of HPS and those science teachers who might be willing to adopt many of the ideas about the role and benefits of HPS in science teaching, which often haven been put forward in this journal.

The project HIPST aimed at such a bridge building activity. Ten partners from seven European countries as well as Israel contributed to the project between 2008 and 2010. We started from the idea that an effective implementation of HPS in science education has to be supported by particular activities, knowledge and materials.

Activities should contribute to connecting different stakeholders in the field of science education and HPS like science teachers, teacher trainers, historians and philosophers of science, curriculum developers, experts for science museums and school science administration. For the sake of this objective, several national conferences in each of the participating countries and international meetings among project partners have been held. ${ }^{1}$

Knowledge from several fields of science, science education and teaching, history and philosophy of science should inform all activities and products of the project. It was assumed that this objective would be achieved best, if people with different expertise bring their specific capacities and perspectives into the project.

\footnotetext{
${ }^{1}$ Minutes of national meetings as well as all case studies develped within HIPST are documented in the project's wikispace (www.hipst.eu). See also the papers presented at the final conference (www.hipst. uni-hamburg.de).
}

D. Höttecke $(\bowtie)$

University of Hamburg, Hamburg, Germany

e-mail: dietmar.hoettecke@uni-hamburg.de 
Educational materials finally should support science teachers and experts of science museums to implement HPS in a more sustained way.

Members of the project consortium decided to develop case studies for teaching and learning in the respected educational fields. More than thirty case studies therefore have been developed and tried out in close collaboration with practitioners of science teaching. General methodological and theoretical considerations of the HIPST project have been outlined by Höttecke, Henke and Rieß in this issue. The HIPST-case studies were all developed and documented according to an exchange format the project partners had agreed on earlier. Next to a brief abstract and a more concise description of the case study, historical and philosophical background information was provided. Such information was meant to support science teachers who usually are lacking background knowledge in these fields. The case studies thus were designed in such a way that they enable not just learning of students but also of teachers. Since one of the major objectives of HIPST was to enhance teaching and learning about the nature of science (NOS) with HPS, the case studies address learning objectives related to the NOS explicitly. Further on, information about the target group, age range, scientific concepts and process skills addressed by the case had to be specified as well as expected effects on students' interests and motivation. All this information should enable a quick orientation and navigation through the case studies. In order to support science teachers as effectively as possible all designed materials and activities like worksheets, questionnaires, instruments, inquiry and role-play activities, pictures and films have to be included in the materials.

From the perspectives of most of the science teachers HPS appears to be a curricular innovation which threatens their usual practices and routines of teaching. Therefore, obstacles for teaching and learning had to be identified and ways of how the case studies deal with them had been developed and described in detail. We have assumed HPS to be a means to open up science education towards a less teacher-oriented and a more studentcentered approach. Thus, specific pedagogical skills were required, for instance to moderate open-ended discussions about scientific controversies, to guide role-play activities or to address NOS issues explicitly and reflectively in the classroom. All in all, the HIPST case studies should cover extended guidance for science teachers in order to encourage and enable them to teach science with HPS.

Quality standards for the HIPST project are an important instrument for clarifying and unifying the quality of its outcomes. All case studies were reviewed and discussed by members of the project's advisory board in the light of these standards.

The case studies designed for school science education should satisfy the following standards:

The case studies: ...

- are documented completely and comprehensively, including the specification of possible target groups, guidelines for teachers, documentation of prerequisites for the learners, a list of educational objectives (learning goals) and a list of media, both already available and to be created

- focus on different target groups of students (high and low abilities in science, different cultures and social backgrounds)

- are adapted to the needs and boundary conditions of the educational practices of school science teaching and accepted by science teachers

- are adapted to differing national conditions regarding language and cultural issues

- promote students' learning of scientific concepts as well as the nature of science

- consider science as developmental, changeable, tentative and contingent 
- portray science as rooted in culture, history and society as a whole, as a culture itself and as a human endeavor

- avoid whiggish views on history of science which means that a direct storyline from the past to the present is avoided

- combine the ideas of learning with History and Philosophy of Science (HPS) and inquiry learning

The HIPST case studies all do allow public access by a project wiki as Allchin in this special issue has asked for in order to enhance their dissemination. A wide range of groups from primary education up to teacher training have been targeted. Content covers cases from the history of biology, chemistry with a slight predominance of physics.

The articles in this HIPST-special issue cover a selection of project results. Results also encompass research in the history and philosophy of science which may be useful for informing future development of further case studies.

Dietmar Höttecke, Andreas Henke and Falk Rieß provide extended insights into the foundations of the HIPST project. They justify the development of case studies as an appropriate format for teaching and learning science with HPS. Subsequently, the basic assumptions of the developmental work of the German HIPST groups are described and justified. Based on the fundamental problem of bridge-building between the academic culture and the culture of school science education a model of collaboration will be described. According to this model different kinds of expertise are brought into cycles of development, evaluation and refinement of case studies. Students' perspectives have to be considered consequently within an adapted model of educational reconstruction. The article demonstrates moreover, how several kinds of student-centered activities serve as a methodological basis for improving an HPS approach of teaching and learning science. Since a major objective of HIPST was to enhance learning about the NOS, the "reflection corner" will be introduced as a method to reflect on the NOS explicitly.

Douglas Allchin introduces us to the Minnesota case study collection which might be regarded as a more well known complement to what has been achieved in the HIPST project. While HIPST has aimed at bringing together an HPS and an inquiry-learning approach, the Minnesota case study collection similarly is arguing for the engagement of students through open-ended problems and questions within historical contexts. According to Allchin case studies for teaching and learning science based on HPS should be well informed not only by HPS, but also by sociology. NOS problems should be situated in concrete contexts instead of abstract metaphysical spaces in order to foster scientific literacy more effectively. The article covers a wide range of short descriptions of case studies. The article thus provides an overview of what already has been achieved within the Minnesota framework including the central ideas behind the development of case studies.

Igal Galili briefly presents in his paper several case studies developed for HIPST. The case studies are concerned with the Cartesian theory of motion, pre-newtonian theories of motion, the history of models and theories about the explanation of optical images and vision, weight and gravitational forces, and the history of inertial forces. The cases thus cover a wide range of ideas of how to embed the history of concepts in physics in a wider cultural context. Galili shows how the case studies may contribute to the development of cultural content knowledge, how he calls it. According to him such knowledge is appropriate to improve pedagogical content knowledge of science teachers and to facilitate meaningful learning of students.

Cibelle Celestino Silva demonstrates in her article how science and society might be interrelated. She focuses Newton's studies of optics and demonstrates that the common 
notion of Newton as an advocate of the corpuscular theory of light is not supported by historical studies in a narrow sense. Instead, Newton also used a model describing the innate properties of rays of light called fits of easy reflection and easy transmission. Newton's followers, the Newtonians, instead did not just follow their master. They ignored a wide part of Newton's work especially his central concept of fits of easy transmission and easy reflection of light. Moreover, important natural philosophers successively transformed Newton's queries or hypotheses about the corpuscular nature of light into an assertion. The consequence of such a behavior was that the optical models of the Newtonians were merely based on a choice of Newton's original ideas. Even though Newton had used various hypothetical explanations to explain a variety of phenomena and to structure his ideas, he became well known as a good example of an inductivist until today. Silva's article not only puts this view into question. She also illustrates how Newton's prestigious status has influenced his reception. The case generally demonstrates that science is a human enterprise which produces tentative and changing knowledge. Her article illuminates what the term "human" might mean in the special relation of Newton and the Newtonians.

Ricardo L. Coelho discusses central conceptual problems in the foundation of mechanics based on historical studies about the law of inertia. He identifies problems concerning the law of inertia, the concept of force including fictitious forces, weight, mass, and the distinction between inertial and gravitational mass. He proceeds with discussing the law of inertia as the source of several conceptual problems. These problems could be overcome if we start with acceleration instead of the law of inertia. This starting-point is justified because the law of inertia presupposes acceleration necessarily whereas acceleration does not presuppose the law. Moreover, acceleration is determinable, but in the case of accelerated bodies force is not. Therefore, force can only be measured by force meters. In case of accelerated bodies, we regard acceleration as an observable sign of a force acting. But, if we regard force as the cause of acceleration we already have presupposed the conceptual framework of the law of inertia.

Acknowledgements I express my gratitude to the partners of the HIPST project, to mention just some of the key figures: Paulo Brenni, Ricardo Coelho, Igal Galili, John Oversby, Falk Rieß, Fanny Seroglou, Jozefina Turlo and Gábor Zemplén. Additional thanks to Falk Rieß who's continuing support already has let to a successful project proposal. I feel grateful to the members of the project's advisory board for having supervised the project and evaluated its products: Douglas Allchin, Thomas Bethge, Augustin Adúriz-Bravo, Marianne Ødegaard, Cibelle C. Silva, Georg Trendel and Anneliese Wellensiek. Many thanks also to a great number of people who have been involved in HIPST. Several science teachers in different countries have put an enormous effort on the development of case studies. Research and development were supported by the 7th Framework Programme of the European Commission. 